\title{
HEMOCULTURA: TÉCNICA SENSÍVEL NA DETECÇÃO DO TRUYPANOSOMA CRUZI EM PACIENTES CHAGÁSICOS NA FASE CRÔNICA DA BOOENÇA DE CHAGAS
}

\author{
Zélia M.P. Luz, Micheli G. Coutinho, J. Romeu Cançado e \\ Antoniana U. Krettli
}

\begin{abstract}
A sensibilidade de hemoculturas, realizadas uma ou três vezes, foi estudada em 52 pacientes na fase crônica da doença de Chagas. Modificações foram introduzidas na técnica tais como, diminuição do período de processamento do sàngue, homogeneização suave e exame até 120 dias do cultivo. Os resultados mostram alto percentual de positividade, ou seja, $79 \%$ e $94 \%$ dos pacientes foram positivos, respectivamente, com um ou três testes. A julgar pelo número de tubos positivos, em cada paciente, a parasitemia foi baixa em $59 \%$ deles, média em $16 \%$ e altc em $25 \%$. Não houve diferenças significativas nos resultados positivos em função da idade dos pacientes, que variou de 14 a 82 anos. Nossos resultados demonstram que a hemocultura é um a metodologia sensivel parao diagnóstico parasitológico da doença de Chagas e ideal para monitorar cura em pacientes submetidos a tratamento .
\end{abstract}

Palavras-chaves: Hemocultura. Trypanosoma cruzi. Cura parasitológica. Paciente chagásico.

O diagnóstico da doença de Clagas, em pacientes ma fase crônica, é realizado principalmente através de testes sorológicos convencionais tais como, imunofluorescência indireta, hemaglutinação e fixação do complemento. Tal fato é decorrente dos baixos níveis de parasitemia, característicos, dessa fase da doença ${ }^{2}$. No entanto, apćs o tratamento específico, a sorologia convencional pode permanecer positiva por longos períodos nos pacientes que aparentemente eliminaram o parasita 7 10. Camundongos tratados com nifurtimox ou benzonidazol também apresentain a sorologia convencional positiva na total ausência de infecção ativa $^{1}$. Portanto, a introdução de metodologias capazes de evidenciar o Trypanosoma cruzi no paciente chagásico, com o objetivo de discriminar indivíduos curados de não curados, torna-se fundamental. A hemocultura e o xenodiagnóstico,

Centro de Pesquisas René Rachou/Furdação Oswaldo Cruz e Faculdade de Medicina da Universidade Federal de Minas Gerais, Belo Horizonte, MG.

Apoio financeiro: CNPq e Programa de Apoio à Pesquisa (PAPES) - FIOCRUZ

Endereço para correspondência: Profa. Antoniana Ursine Krettli. Laboratório de Malária - Centro de Pesquisas René Rachou/FIOCRUZ, Caixa Postal 1743, 30161-970 Belo Horizonte, MG; Fax: (031) 295-3115.

Recebido para publicação em 13/01/94. métodos parasitológicos mais usados na pesquisa do $T$. cruzi, em pacientes crônicos, detectam o parasita em cerca de $50 \%$ dos casos, quando o teste é realizado uma única vez 5 . Recentemente, na Argentina, hemoculturas realizadas até 8 vezes em 90 chagásicos crônicos não tratados, foram positivas em $86,6 \%$ dos pacientes 9 . Em trabalho recente, demonstramos que hemoculturas realizadas uma única vez em 101 pacientes não tratados resultaram em $47 \%$ de positividade, enquanto com duas hemoculturas em 13 chagásicos não tratados a positividade foi de $56 \%$. Entretanto, todas as hemoculturas foram persistentemente negativas em pacientes tratados e curados assim como nos dissociados nos quais a pesquisa de anticorpos líticos foi negativa apesar da sorologia convencional positiva?

$\mathrm{Na}$ tentativa de tornar a técnica de hemocultura mais sensivel foram introduzidas modificações a fim de se reduzir o tempo de manuseio do parasita durante o processamento do sangue e favorecer a sua multiplicação no cultivo. A positividade do teste foi avaliada, em 52 chagásicos não tratados na fase crônica da doença, em função do número de vezes que a hemocultura foi realizada, do número de tubos positivos e da faixa etária dos pacientes. 
Luz ZMP, Coutinho MG, Cançado JR, Krettli AU. Hemocultura: técnica sensivel na detecção do Trypanosoma cruzi em pacientes chagásicos na fase crônica da doença de Chagas. Revista da Sociedade Brasileira de Medicina Tropical 27:143-148, jul-set, 1994.

\section{MATERIAL E MÉTODOS}

Pacientes chagásicos: 52 pacientes não tratados na fase crônica da infecção pelo $T$. cruzi, com pelo menos 3 reações sorológicas positivas para antígenos do parasita, foram submetidos a hemocultura. Desse total 34 eram mulheres e 18 eram homens, com idades variando de 14 a 82 anos (Tabela 1). O número de hemoculturas realizadas e o intervalo entre as coletas de sangue foram definidos em função da disponibilidade dos pacientes sendo em média de 2 a 4 semanas e de no máximo 3 meses. Todos os chagásicos dessa amostra não haviam se submetido, anteriormente, a qualquer teste parasitológico para doença de Chagas e desses, 34 realizaram três testes seriados.

Tabela 1 - Total de hemoculturas positivas em 52 pacientes chagásicosnão tratados em função da faixa etária submetidos a uma única hernocultura.

\begin{tabular}{rcccc}
\hline $\begin{array}{r}\text { Faixa } \\
\text { etária }\end{array}$ & \multicolumn{2}{c}{ Pacientes } & \multicolumn{2}{c}{$\begin{array}{c}\text { Positivos/Total } \\
\text { examinados }\end{array}$} \\
\hline $0-19$ & 1 & 1 & $2 / 2$ & $100 \%$ \\
$20-39$ & 9 & 12 & $19 / 21$ & $90 \%$ \\
$40-59$ & 6 & 18 & $17 / 24$ & $71 \%$ \\
$>60$ & 2 & 3 & $4 / 5$ & $80 \%$ \\
\hline
\end{tabular}

Hemocultura: A técnica utilizada foi baseada na descrita por Chiari e cols. $1989^{6}$ com modificações. Resumidamente, $30 \mathrm{ml}$ de sangue foram coletados de cada paciente em tubos "Vacutainer" heparinizados, transferidos para tubo Falcon 2070 e imediatamente centrifugados após a coleta $(4000 \mathrm{~g}$ $10 \mathrm{~min} 4^{\circ} \mathrm{C}$ ). O plasma foi cuidadosamente removido para tubo de $15 \mathrm{ml}$ Falcon 2095, a fim de não ser aspirada a camada leucocitária, e novamente centrifugado $\left(4000 \mathrm{~g} 20 \mathrm{~min} 4^{\circ} \mathrm{C}\right)$. O sobrenadante foi retirado, aliquotado e estocado a $-20^{\circ} \mathrm{C}$ para as reações sorológicas posteriores. Ao sedimento do plasma foram adicionados $4 \mathrm{ml}$ do meio de cultura "Liver Infusion Tryptose" (LIT) ${ }^{3}$. O sedimento de hemácias contendo a camada leucocitária foi lavado uma vezem LIT ( $4000 \mathrm{~g} 20 \mathrm{~min} 4^{\circ} \mathrm{C}$ ), ressuspendido em $10 \mathrm{ml}$ do meio de cultura e distribuído em 6 tubos Falcon 2095 contendo $2 \mathrm{ml}$ do LIT cada. Usando esse procedimento o tempo gasto para processar a hemocultura foi de, no máximo, 30 minutos. As culturas foram mantidas a $28^{\circ} \mathrm{C}$, homogeneizadas, suavemente, uma vez por semana e alíquotas de $10 \mu l$ da suspensão, de cada tubo, examinadas mensalmente, entre lâmina e lamínula, durante 120 dias ao microscópio ótico.

\section{RESULTADOS}

Dos 34 pacientes chagásicos não tratados que realizaram três hemoculturas sucessivas, 32 (94\%) foram positivos, sendo 27 (79\%) no primeiro teste, $4(12 \%)$ no segundo e 1 (3\%) no terceiro. As hemoculturas de dois pacientes foram negativas após os três testes realizados. A percentagem cumulativa de positividade nos três testes está ilustrada na Figura 1. Na maior parte dos pacientes os resultados foram positivos aos 30 dias (48\%) e 60 dias $(34 \%)$ respectivamente. No entanto, $14 \%$ foram positivos somente aos 90 dias e $4 \%$ aos 120 dias de cultivo (Figura 2).

A possível influência da idade do paciente na positividade da hemocultura foi analisada somente após o primeiro exame. O número de indivíduos estudados por faixa etária foi variável sendo que a maioria deles ( $86 \%$ ) ficou concentrada no intervalo de 20 a 59 anos. Em todas as faixas etárias havia homens e mulheres. As hemoculturas foram positivas nos 2 pacientes mais jovens (14 e 19 anos); em 19 dos 21 pacientes entre 20 a 39 anos; em 17 dos 21 pacientes entre 40 a 59 anos; e, em 4 dos 5 pacientes com sessenta anos ou mais (Tabela 1). Portanto, foi alto o percentual de resultados positivos nas diferentes faixas etárias variando de $71 \%$ a $100 \%$. Não houve diferença estatística significante entre os grupos utilizando o teste do qui-quadrado $p=0,06$.

Onível de parasitemia dos pacientes foi estimado através da positividade dos 6 tubos utilizados para cada exame. Pacientes com apenas 1 ou 2 tubos positivos foram considerados de baixa parasitemia; com 3 tubos positivos de média parasitemia, e, com 4 ou mais tubos positivos de alta parasitemia. Utilizando esse parâmetro, verificamos que entre os 52 pacientes, $31(59 \%)$ apresentaram baixa parasitemia, $8(16 \%)$ média e $13(25 \%)$ alta parasitemia (Figura 3).

Quando analisamos o número de tubos positivos em função da faixa etária dos pacientes observamos que os 2 chagásicos mais jovens e os 5 mais idosos apresentaram baixa parasitemia. Nos outros dois grupos etários ( 20 a 39 e 40 a 59 anos) totalizando 
Luz ZMP, Coutinho MG, Cançado JR, Krettli AU. Hemocultura: técnica sensível na detecção do Trypanosoma cruzi em pacientes chagásicos na fase crônica da doença de Chagas. Revista da Sociedade Brasileira de Medicina Tropical 27:143-148, jul-set, 1994.

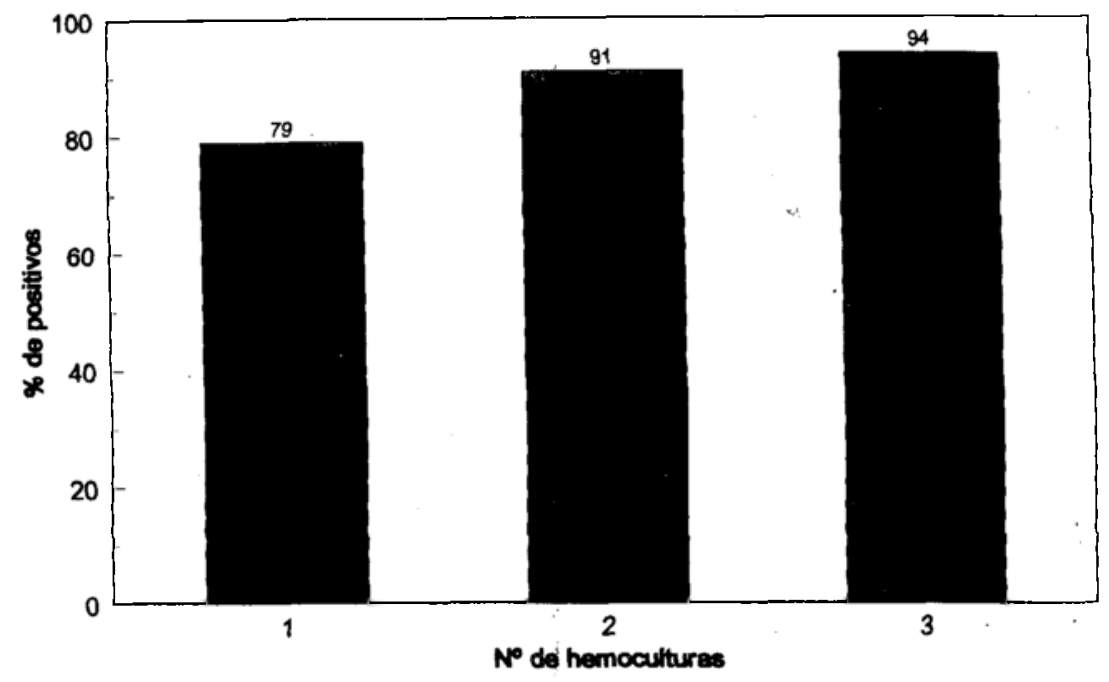

Figura 1 - Positividade cumulativa de três hemoculturas sucessivas em 34 chagásicos, não tratados, na fase crônica da doença de Chagas.

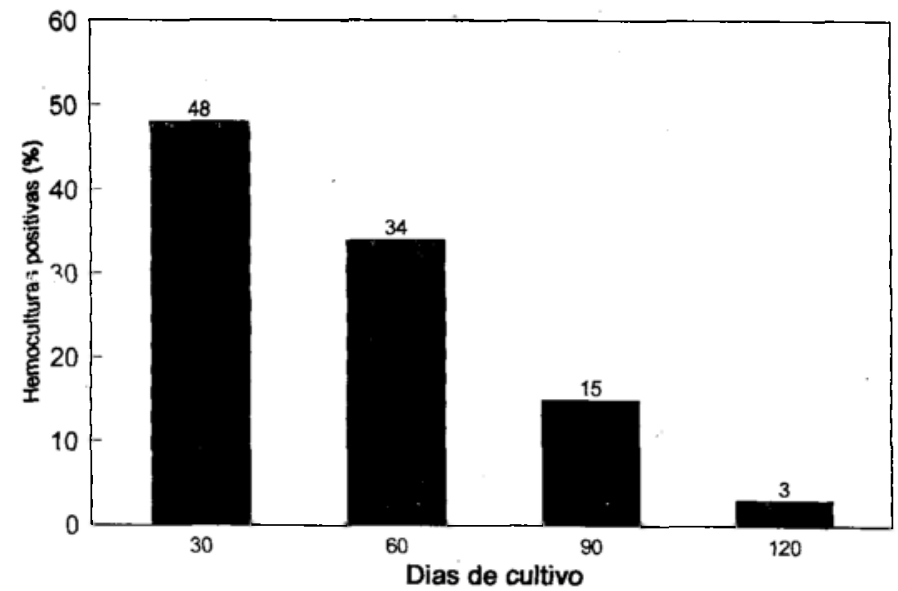

Figura 2 - Positividade da hemocultura em 52 pacientes chagásicos não tratados em função do tempo de cultivo.

45 pacientés $23(51 \%)$ apresentaram baixa parasitemia, $7(15 \%)$ pacientes média parasitemia e $12(27 \%)$ pacientes alta parasitemia. Portanto, a maioria dos pacientes apresentou parasitemia baixa, independentemente da sua idade (Figura 4).

\section{DISCUSSÃO}

Evidenciar o Trypanosoma cruzi no paciente chagásico, através de testes parasitológicos, é a forma definitiva de caracterizar a infecção ativa; no entanto na fase crônica da doença a positividade desses testes, em geral, é baixa. A utilização da hemocultura tem sido deixada em segundo plano principalmente pelos resultados negativos obtidos por alguns autores ${ }^{5}$, com isso o xenodiagnóstico, também de sensibilidade reduzida, tem sido o método parasitológico mais amplamente empregado apesar da complexidade que envolve a interação parasita-vetor ${ }^{8}$, provavelmente uma das causas que mais concorre para a baixa sensibilidade do xenodiagnóstico. Além disso, esse método de 
Luz ZMP, Coutinho MG, Cançado JR, Krettli AU. Hemocultrura: técnica sensível na detecção do Trypanosoma cruzi em pacientes chagásicos na fase crônica da doença de Chagas. Revista da Sociedade Brasileira de Medicina Tropical 27:143-148, jul-set, 1994.

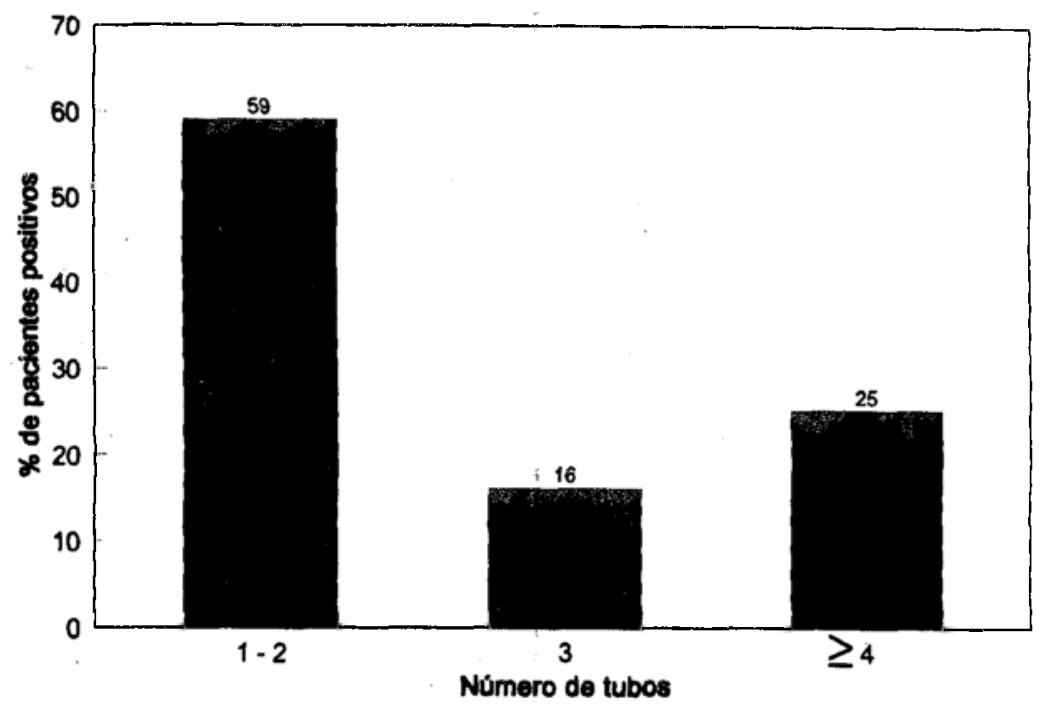

Figura 3 - Percentagem de chagásicos não tratados'com hemoculturas positivas em função do número de tubos com parasitas.

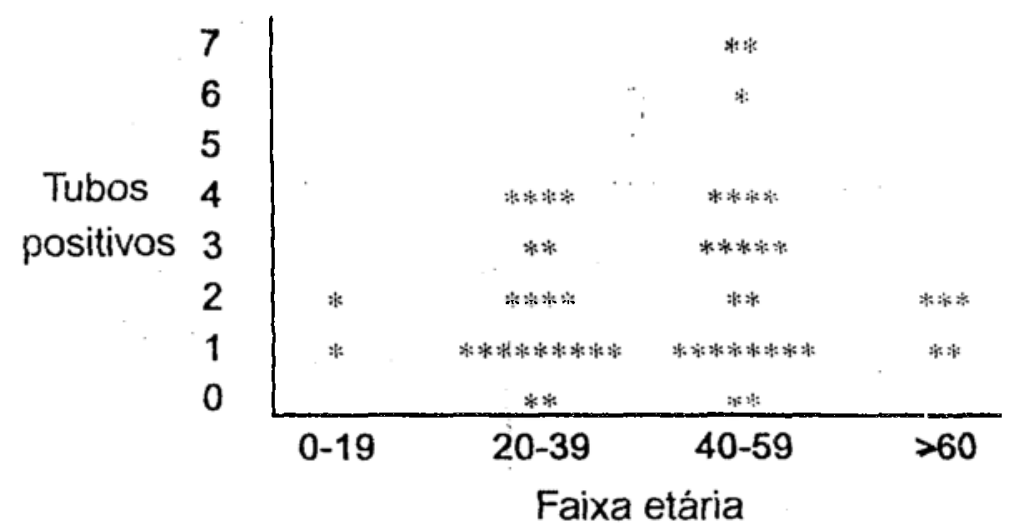

Figura 4 - Distribuição do número de tubos positivos por paciente nas diferentes faixas etárias em 52 chagásicòs não tratados.

diagnóstico exige insetário com grande número de insetos que sejam biologicamente constantes ${ }^{4}$.

Na hemocultura a positividade parece depender tanto da natureza do meio de cultura como da técnica empregada e modificações na metodologia têm proporcionado resultados mais positivos. Assim coletar maiores volumes de sangue do paciente, retirar fatores inibidores do crescimento do parasita, prolongar o tempo de cultivo e realizar o teste repetidas vezes têm sido as abordagens mais usadas com sucesso ${ }^{6}{ }^{11}$. Os resultados nesse trabalho mostraram que três hemoculturas foram capazes de detectar o T. cruzi em $94 \%$ dos pacientes. No entanto, mesmo com um único teste, encontramos $79 \%$ dos pacientes positivos. Algumas modificações foram feitas no protocolo da hemocultura visando reduzir a manipulação do sangue, na tentativa de manter o parasita mais viável e em condições favoráveis de multiplicação mais rápida. Assim o tempo total para processar a hemocultura foi reduzido para no máximo 30 minutos, as hemácias foram lavadas uma só vez no meio de cultura LIT, e o teste foi feito imediatamente após a coleta do sangue. Esses, possivelmente, são os fatores críticos 
'uz ZMP, Coutinho MG, Cançado JR, Krettli AU. Hemocultura: técnica sensivel na deteç̧ão do Trypanosoma cruzi ?m pacientes chagásicos na fase crônica da doença de Chagas. Revista da Sociedade Brasileira de Medicina Tropical 27:143-148, jul-set, 1994.

responsáveis pela elevada sensibilidade da hemocultura descrita nesse trabalho.

O tempo prolongado de cultivo (120 dias) demonstrou ser importante. De modo geral a maior parte dos autores fazem o último exame da hemocultura aos 45 ou 60 dias do cultivo. Entretanto, nesse trabalho cerca de $20 \%$ dos pacientes só se positivaram mais tardiamente, após os 60 dias da cultura, corroborando dados anteriores? ${ }^{7}$. Outra possibilidade para explicar a maior positividade, com apenas uma hemocultura, poderia ser a parasitemia elevada dos pacientes com os quais trabalhamos. Se na nossa amostra prevalecessem chagásicos de alta parasitemia, mesmo com uma única hemocultura o índice de positividade dos tubos examinados seria elevado. Entretanto, nos mossos resultados $59 \%$ dos pacientes foram de baixa parasitemia, isto é, com um ou dois tubos positivos dos seis examinados. Portanto não trabalhamos somente com pacientes de alta positividade. $\mathrm{Na}$ classificação da parasitemia dos pacientes, entretanto, mão levamos em consideração possíveis dificuldades adaptativas e nutricionais que poderiam influenciar no crescimento do parasita nas condições do nosso trabalho ${ }^{12}$.

A hemocultura foi capaz de detectar o T. cruzi nos pacientes, independentemente do tempo de infeç̧ão já que não foram observadas diferenças significativas na positividade das hemoculturas nas várias faixas etárias dos pacientes. Nos diferentes grupos verificamos um alto percentual de positivos, mesmo entre os mais idosos, entre 64 a 82 anos. Apesar da amostra ser pequena nesse grupo, $80 \%$ deles foram positivos na primeira hemocultura e $100 \%$ ao final dos três testes. Todos apresentaram, no entanto, baixa parasitemia, isto é, um a dois arbos positivos. Esses pacientes, provavelmente possuem a doença há mais de 50 anos se considerarmos que todos se infectaram na primeira década de vida. Os dois pacientes mais jovens (14 e 19 anos), positivos pela hemocultura, também apresentaram baixa parasitemia ajulgar pelo número de tubos positivos. No entanto, como o número de undivíduos nesses dois grupos foi baixo, possíveis imferências relacionadas ao grau de parasitemia wersus idade necessitam ser melhor investigadas muma amostragem maior de pacientes.

Nossos resultados, mostram que a técnica de themocultura, com as modificações na metodologia aqui introduzidas, revelou parasitas num percentual elevado de pacientes chagásicos não tratados, na fase crônica, a despeito da sua idade e da sua parasitemia, medida pelo número de tubos positivos, em geral, baixa. A hemocultura demonstrou portanto, ser um teste sensível no diagnóstico da doença de Chagas sendo ideal como critério de cura de chagásicos submetidos a tratamento. Nesses pacientes, hemoculturas persistentemente negativas são um forte indicador de cura parasitológica, mesmo que a sorologia convencional seja persistentemente positiva.

\section{SUMMARY}

The sensitivity of hemocultures, performed once or three times, was invesigated in 52 patients in the chronic phase of Chagas disease. Modifications were introduced in the technique such as, processing the blood more rapidly, gently homogenizing the cultures and examining them afier 120 days of culture. Our results show a high percent age of positivity i.e. $79 \%$ and $94 \%$ of patients submitted, respectively, to one or three tests. No significant differences related to the patients age were detected, which varied from 14 to 82 years old. Our results demonstrate that hemoculture is a sensitive method for the parasitological diagnosis of Chagas disease and is ideal for monitoring cure in treated patients.

Key-words: Hemoculture. Trypanosoma cruzi. Parasitological cure. Chagasic patients.

\section{AGRADECIMENTO}

Ao Prof. Zigman Brener pela leitura crítica do manuscrito e sugestões.

\section{REFERÊNCIAS BIBLIOGRÁFICAS}

1. Andrade SG, Freitas LAR, Peyrol S, Pimentel AR, Sadigursky M. Trypanosoma cruzi antigens detected by Immunoelectron microscopy in the spleen of mice serologically positive but parasitologically cured by chemotherapy. Revista da Sociedade Brasileira de Medicina Tropical 21:41-42,1988.

2. Brener $Z$. Immune response and immunopathology in T.cruzi infection. In: WendelS, Brener Z, Camargo ME, Rassi A (eds) Chagas Disease (American Trypanosomiasis): its Impact on Transfusion and Clinical Medicine, $1^{\text {st }}$ edition, ISBT Brazil'92, São Paulo p.31-47, 1992.

3. Camargo EP. Growth and differentiation in 
ZuzZMP, Coutinho MG, Cançado JR, Krettli AU. Hemocultura: técnica sensivel na detecção do Trypanosoma cruzi em pacientes chagásicos na fase crônica da doença de Chagas. Revista da Sociedade Brasileira de Medicina Tropical 27:143-148, jul-set, 1994.

Trypanosoma crazi. I. Origin of metacyclic trypanosomes in liquid media. Revista do Instituto de Medicina Tropical de São Paulo 6:93-100,1964.

4. Cerisola JA, Rohwedder R, Segura EL, Del Prado CE, Alvarez $M$, De Martini GJW. E1 Xenodiagnóstico. Instituto Nacional de Diagnóstico e Investigacion de la Enfermedad de Chagas "Dr. Mário Fatala Chaben", Buenos Aires, p.1-111, 1974.

5. Chiari E, Brener Z. Contribuição ao diagnóstico parasitológico da doença de Chagas na sua fase crônica. Revista do Instituto de Medicina Tropical de São Paulo 8:134-138, 1966.

6. Chiari E, Dias JCP, Lana M, Chiari CA. Hemocultures for the Parasitologycal Diagnosis of Human Chronic Chagas' Disease. Revista da Sociedade Brasileira de Medicina Tropical 22:1923, 1989.

7. Galvão LMC, Nunes RMB, Cançado JR, Brener Z, Krettli AU. Lytic antibody titre as a means of assessing cure after treatment of Chagas disease: a 10 years follow-up study. Transactions of the Royal Society of Tropical Medicine and Hygiene 87:220223, 1993.
8. Garcia ES, Azambuja P. Development and Interactions of Trypanosoma cruzi within the insect vector. Parasitology Today 7:240-244, 1991

9. Jorg ME, Baez VJ. Parasitemia en infectados cronicos por Trypanosoma cruzi, indeterminados $\mathrm{y}$ sintomaticos, evidenciada por hemocultivo. Publicación Médica 6:71-79, 1993

10. Krettli AU, Cançado JR, Brener Z. Effect of specific chemotherapy on the levels of lytic antibodies in Chaga's disease. Transactions of the Royal Society of Tropical Medicine and Hygiene 76:334-340, 1982.

11. Minter-Goedbloed E, Minter DM, Marshall TFC. Quantitativecomparison between xenodiagnosis and haemoculture in detection of Trypanosoma (Schizotrypanum) cruzi in experimental and natural chronic infections. Transactions of the Royal Society of Tropical Medicine and Hygiene 72:217-225, 1978.

12. Neal RA, Miles RA. The sensitivity of culture methods to detect experimental infections of Trypanosoma cruzi and comparison with xenodiagnosis. Revista do Instituto de Medicina Tropical de São Paulo 19:170-176, 1977. 